\title{
Paisagem urbana, vulnerabilidade e risco em brejos de altitude: 0 sítio urbano de Areia/PB
}

A expansão urbana nos países subdesenvolvidos pode se tornar um problema catastrófico quando acontece em terrenos ambientalmente instáveis. A geomorfologia urbana é a ciência que estuda os sítios urbanos pelo viés das características do relevo e suas interrelações com outros componentes da paisagem, como o clima, meteorologia, geologia, vegetação e uso e ocupação. A partir do delineamento geoambiental da paisagem urbana com uso do geoprocessamento, sensoriamento remoto e análise empírica, esta pesquisa tem por objetivo geral retratar a interface geomorfológica do sitio urbano de Areia-PB e, especificamente, identificar paisagens de risco urbano através da matriz geossistêmica. Como resultado, tem-se áreas com ocupação irregular e construções frágeis em terrenos íngremes. É plausível que esta pesquisa venha a direcionar e possibilitar outras, que aprofundem mais os levantamentos dos problemas de ordenamento territorial do sitio urbano de Areia e possa subsidiar políticas publicas urbanas.

Palavras-chave: Expansão urbana; Geoambiental; Terrenos íngremes.

\section{Urban landscape, vulnerability and risk in mountain ranges: the urban site of Areia/PB}

\begin{abstract}
Urban sprawl in underdeveloped countries can become a catastrophic problem when it occurs on environmentally unstable ground. Urban geomorphology is the science that studies the urban sites due to the bias of the relief features and its interrelations with other components of the landscape, such as climate, meteorology, geology, vegetation and use and occupation. Based on the geo-environmental design of the urban landscape using geoprocessing, remote sensing and empirical analysis, this research aims to portray the geomorphological interface of the Areia-PB urban site and, specifically, to identify landscapes of urban risk through the geosystemic matrix. As a result, there are areas with irregular occupation and fragile constructions on steep terrain. It is plausible that this research will direct and enable others, which will deepen the surveys of the problems of territorial planning of the urban site of Areia and can subsidize urban public policies.
\end{abstract}

Keywords: Urban sprawl; Geoenvironmental; Steep terrain.

Topic: Geomorfologia

Reviewed anonymously in the process of blind peer.

Ailson de Lima Marques

Universidade Federal da Paraíba, Brasil

http://lattes.cnpq.br/7731519684534647

marques.ailsonl@gmail.com

Ewerton da Silva Barbosa

Universidade Federal da Paraíba, Brasil

http://lattes.cnpq.br/9038746208521577

ewertonbarbosa@hotmail.com

Jose Kennedy do Nascimento Ribeiro

Universidade Federal da Paraíba, Brasil

http://lattes.cnpq.br/0509502439867132

kennedy ribeiro@hotmail.com
Received: 16/08/2017

Approved: 09/11/2017

\author{
Ester dos Santos Coelho \\ Universidade Federal da Paraíba, Brasil \\ http://lattes.cnpq.br/5549290976917474 \\ ester_coelho22@gmail.com \\ Elysson Thiago Gomes Barbosa \\ Universidade Federal da Paraíba, Brasil \\ http://lattes.cnpq.br/7998948391547412 \\ elyssonthiago1@hotmail.com
}

DOI: $10.6008 / S P C 2318-2881.2017 .002 .0003$

Referencing this:

MARQUES, A. L.; BARBOSA, E. S.; RIBEIRO, J. K. N.; COELHO, E. S.; BARBOSA, E. T. G.. Paisagem urbana, vulnerabilidade e risco em brejos de altitude: o sítio urbano de Areia/PB. Nature and Conservation, v.10, n.2, p.25-34, 2017. DOI: http://doi.org/10.6008/SPC23182881.2017.002.0003 


\section{INTRODUÇÃO}

As pesquisas geomorfológicas em sítios urbanos no Brasil tiveram início a partir de Ab’Saber (1953; 1965), decorrente da preocupação do autor com a expansão urbana desordenada em áreas com características biofísicas e ambientais propicias a instabilidade geomorfológica. As aglomerações urbanas, em especial as de baixa renda, são responsáveis pelo processo de expansão permanente que, no Brasil, bem como na maior parte dos países subdesenvolvidos, tem desencadeado preocupações de entidades governamentais e não governamentais, devido à aceleração descontrolada dos adensamentos urbanos na paisagem vulnerável.

O relevo e os solos constituem a principal expressão física das condições de equilíbrio na litosfera e a acomodação do homem a esse meio muitas vezes é feita sem respeitar os limites de sua natureza, podendo ocorrer desastres ecológicos diversos e consequentemente perdas de vidas humanas, além de patrimônios privados e coletivos (SAADI, 1997). A geomorfologia urbana se preocupa em estabelecer fieis prognósticos do uso e ocupação na paisagem urbana, bem como sobre as limitações dessa paisagem mediante o ambiente físico e biótico. Nesse contexto, o papel dessa subciência ainda é mais realçado em regiões submetidas a condições bioclimáticas intertropicais e tropicais, onde prevalecem práticas como o desmatamento das Áreas de Preservação Permanentes, com retirada da vegetação em topos de morros e encostas íngremes afim da urbanidade, tendo como resultado os movimentos gravitacionais de massa.

Nos brejos de altitude do interior do Nordeste brasileiro, devido a morfologia de altos topográficos compostos por modelados dissecados sob condições climáticas úmidas e subúmidas, encostas abruptas e pedologia de solos maduros (Argissolos, Latossolos e Vertisolos), os adensamentos urbanos de baixa renda estão susceptíveis a fenômenos de instabilidade geomorfológica. Os brejos de altitude estão presentes nos estados: Ceará, Paraíba, Pernambuco e Rio Grande do Norte como acidentes geográficos orográficos (serras, chapadas, planaltos e platôs), que abrangem cotas de 500 a 1200m, nas superfícies da província Borborema, como se pode visualizar na figura 1.

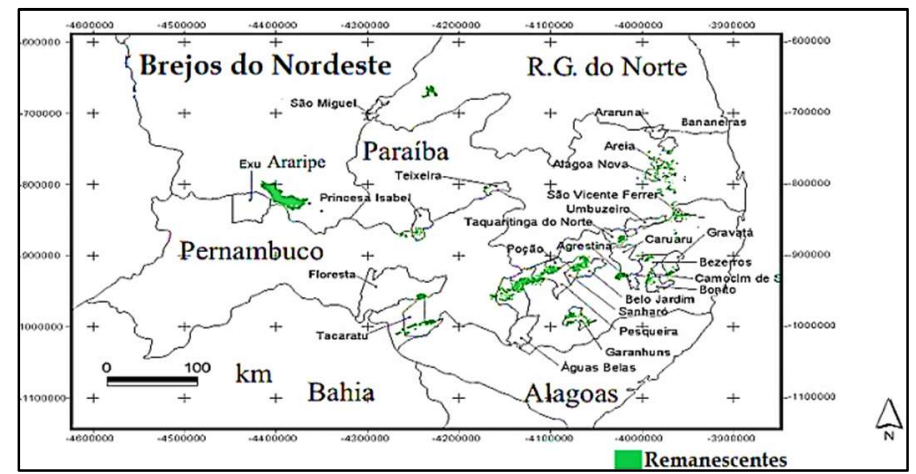

Figura 1: Remanescente de brejos de altitude do interior do Nordeste. Fonte: Santos et al. (2004).

A existência desses ambientes úmidos e sub-úmidos, disjuntos da Mata Atlântica e insularizados pelo semiárido, na zona oriental do Nordeste está associada à ocorrência do Planalto da Borborema (SANTOS et al., 2004) onde apresentam ambientes de altitude (cumes/domos), exposição (ombro/barlavento/chuvas 
orográficas) e posição (sopés/pedimentos/deposição), numa escala topográfica (MARQUES et al., 2014), vista na figura 2.

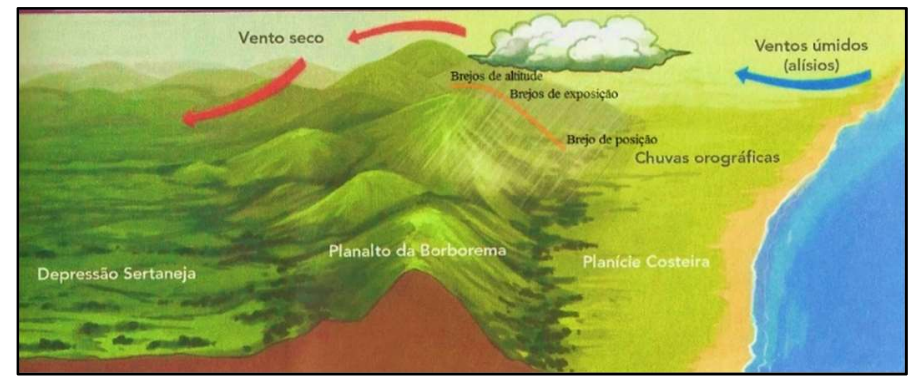

Figura 2: Representação dos brejos de altitude do Planalto da Borborema e chuvas orográficas.

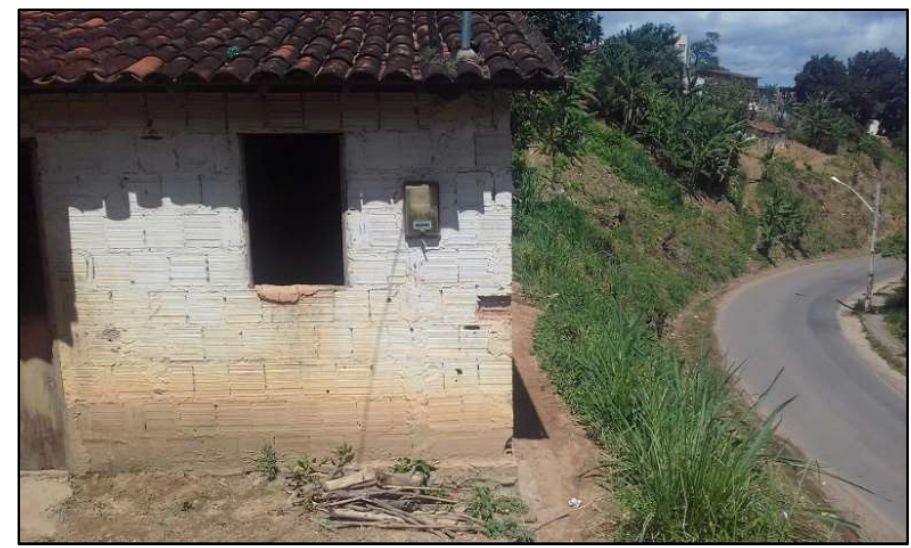

Figura 3: Aspectos da geomorfologia do município de Areia/PB.

No município de Areia, a morfologia urbana, conforme predisposto na figura 3, em especial da periferia, apresenta um perfil de adensamento com nítidas problemáticas ambientais devido o relevo de encostas abruptas e construções frágeis, que resultaram na decisão da prefeitura isolar áreas de eminente risco com remanejamento da população a moradias de locação.

Nesse sentido, entre as muitas ferramentas de geotecnologias para diagnóstico da paisagem urbana vulnerável e de risco, está o geoprocessamento e o sensoriamento $r$ emoto atrelados as concepções metodológicas dos Geossistemas. De acordo com Florenzano (2007), o Sensoriamento Remoto é a ciência ou técnica que permite capturar informações sobre a superfície terrestre por meio de sensores ópticos e radares. O Geoprocessamento é uma ferramenta vinculada a um Sistema de Informações Geográficas - SIG que busca levantamentos, análises e cruzamentos de dados georreferenciados visando a realização do planejamento, manejo e ou gerenciamento de espaços específicos (FITZ, 2008). Para Kimerling (1994), um SIG pode ser definido como um conjunto de hardwares e softwares interligados para a aquisição, armazenamento, estruturação, manipulação, análise e exibição gráfica de dados espacialmente referenciados por coordenadas geográficas.

Entre os muitos produtos e possibilidades dessas ferramentas estão imagens de alta resolução e metodologias que permitem espacializar o espaço geográfico, a partir de Modelos Digitais de Elevação do Terreno-MDE, obtendo-se variáveis morfométricas, como dados hipsometria, declividade, forma de terreno e perfis topográficos em 3D. Nesse propósito, essa pesquisa tem por objetivo geral retratar a interface 
ambiental do sitio urbano de Areia/PB, e especificamente, identificar os locais de risco e vulnerabilidade geomorfológica através de geotecnologias.

\section{METODOLOGIA}

\section{Localização da área de estudo e Caracterização das variáveis geoambientais}

A cidade de Areia é um brejo de altitude que está localizada na microrregião do brejo paraibano, entre as coordenadas geográficas 651'47" e 702'04"S, e 3534'13" e 3548'28”W, (Figura 4). A área urbana apresenta 0,97 $\mathrm{Km}^{2}$, a população residente urbana é de 14.598/hab, e sua densidade demográfica é de 150 hab/Km² (IBGE, 2016). No Mapeamento das áreas de risco e com vulnerabilidades levou-se em consideração o Clima: As- tropical quente e úmido (Köppen-Geiger); precipitação orográfica: médias de 1400 mm/ano; Geologia: complexo granítico sob intemperismo químico (morros) e manchas sedimentares que recobrem os topos dos morros originando mesetas homoclinais; Pedologia: Argissolos amarelos, Argissolos vermelhoamarelos e Latossolos vermelhos.

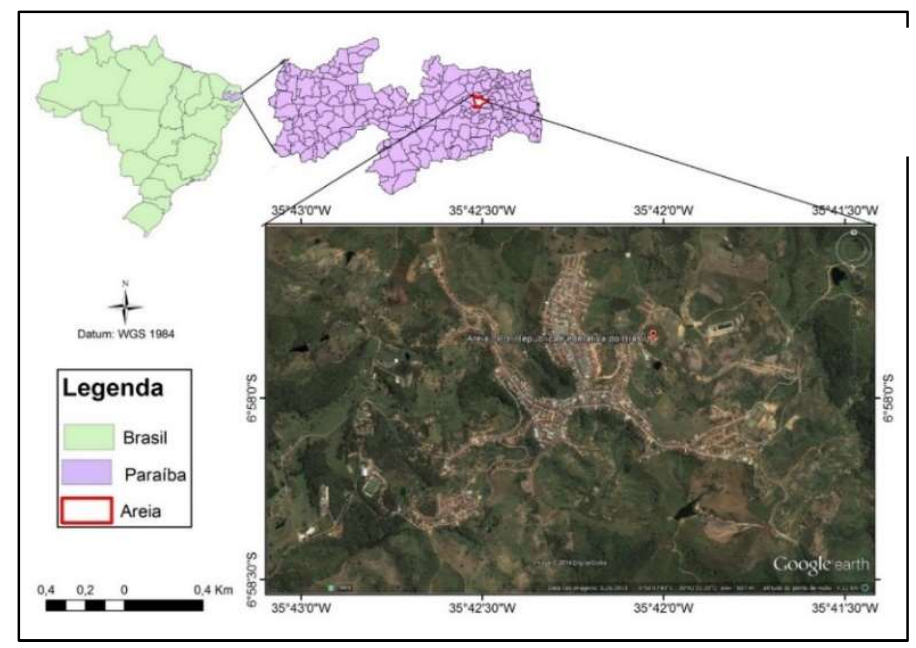

Figura 4: Localização da área de estudo.

\section{METODOLOGIA}

A metodologia dessa pesquisa está embasada em: Ross (1991; 1994), Christopherson (1994), Salomão (1999), CPRM (2003) e Schaefer (2012). Sobre o clima, fenômenos meteorológicos, geologia, geomorfologia, pedologia, biogeografia e uso e ocupação da terra na área urbana, fez-se uma revisão de literatura. Quanto ao mapeamento do sitio urbano, análise da topografia e crescimento urbano, através do software Google Earth Pro, utilizou-se as ferramentas de comparação histórica de Imagens; delimitação poligonal de área e extração de perfis topográficos. No software ArcGIS 10.5, para identificação das vulnerabilidades e espacialização de áreas risco, foram adquiridos e processados os modelos topográficos digitais da área no banco de dados TOPODATA, com resolução espacial de $30 \mathrm{~m}$, onde foram extraídas e analisadas as variáveis: hipsometria e declividade. Através da análise empírica in loco foram analisados todos os bairros do sitio urbano, identificando o arranjo das vulnerabilidades, além disso foram fotografadas as áreas risco. 


\section{RESULTADOS E DISCUSSÃO}

No sítio urbano do município, de acordo com o apresentado na figura 5, tem-se os detalhes do crescimento urbano em relação ao do perfil topográfico do município. O contorno laranja apresenta o delineamento do sitio urbano de 1846 (fundação) até o ano de 1969 e o contorno azul o delineamento de 1970 a 2010. Até 1969 o sitio urbano apresentava uma área estimada em 0,49 km², em 123 anos de ocupação; e em 2010 de 0,97 Km², um crescimento estimado em 0,48 km² (40 anos), ou seja, a partir de 1970 o sitio urbano dobrou seu perímetro em $1 / 3$ do período anterior. O centro do município (centro histórico) se evidenciou com uma ocupação no centro da meseta homoclinal do platô central (superfície plana tabular) até 1969 , e posterior a esse período as ocupações tem ocorrido nas arestas da meseta, onde prevalecem modelados íngremes com risco aos movimentos de massa.

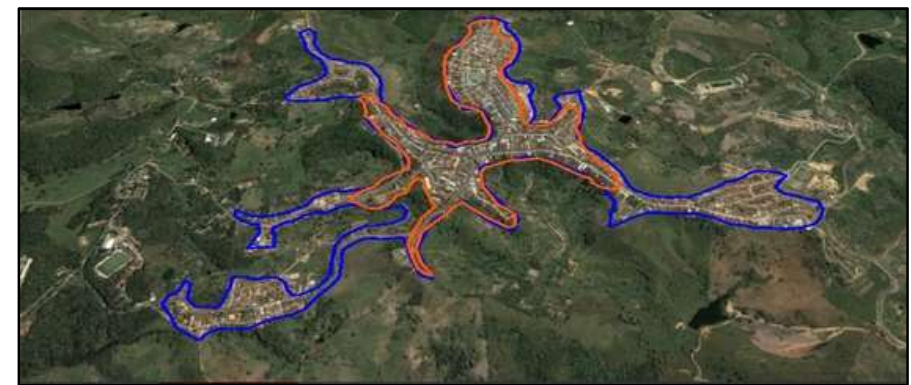

Figura 5: Crescimento urbano e perfil topográfico do sitio urbano de Areia/PB no intervalo temporal de 1846 a 1969 e 1970 a 2010.

Moraes (2005) atribui que a conjuntura do sítio urbano do município de Areia apresenta seu inicio de adensamento populacional em 1701 e dá ao processo de crescimento do município, etapas no intervalo temporal (1701-2005): Primórdios da ocupação (1701-1800); Crescimento territorial expressivo (1801-1850); Interrupção abrupta do crescimento (1851-1900); e Nova fase de crescimento urbano e explosão demográfica, desencadeada a partir do início do século XX (1901-2005).

O intervalo espaço temporal de 1969 a 2010 tecnicamente pertence à época da nova fase de crescimento urbano e explosão demográfica apresentada por Moraes (2008), desencadeada a partir do início do século XX, decorrente da falência dos ciclos agrários, em especial da cana de açúcar, que provou o maior êxodo rural do município desencadeando as aglomerações urbanas frágeis em áreas vulneráveis na periferia.

Ao analisar a conjuntura geomorfológica do sitio urbano do Município, segundo o proposto na figura 6, é verificável a morfologia de morros de topos planos e encosta ravinadas permeadas por morrotes, pedimentos, várzeas e vales, estão representados nas variáveis morfométricas identificadas: altitudes de 509 a 635 e declividades de 15 a 45ㅇ․

Assim, perante a chave de declividade para classificação de terrenos proposta por EMBRAPA (1999), o sitio urbano apresenta terrenos com morfologias ondulada (centro da meseta homoclinal do platô Central) onde a superfície apresenta topografia pouco movimentada, constituída por um conjunto de colinas que 
apresentam declives moderados, e terrenos forte ondulados (arestas e ombros), onde a superfície apresenta topografia movimentada, formada por outeiros e/ou morros com declives fortes.

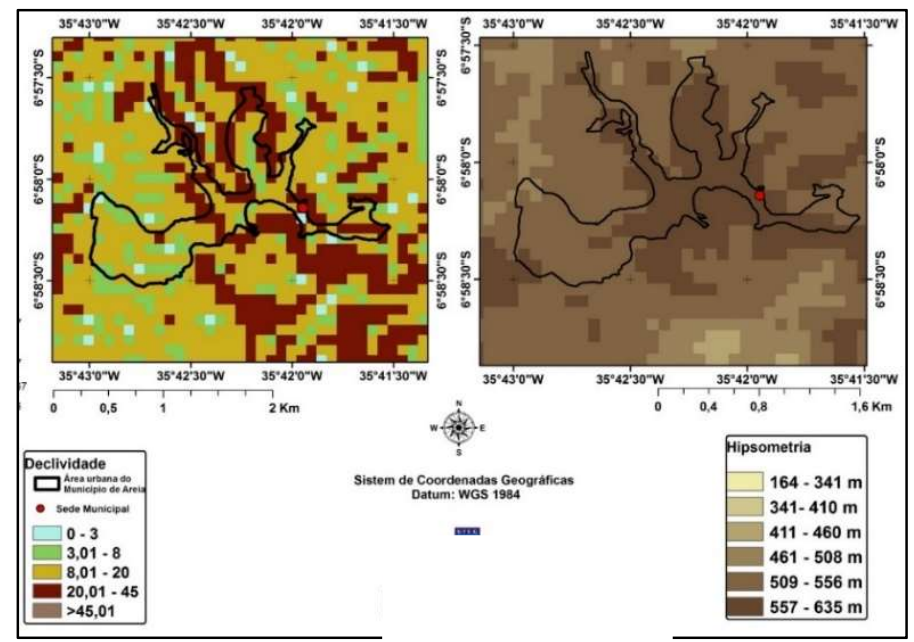

Figura 6: Espacialização da hipsometria (aıtıtuae) e aecııvıaade do sitio urbano de Areia/PB.

\section{Riscos e vulnerabilidades}

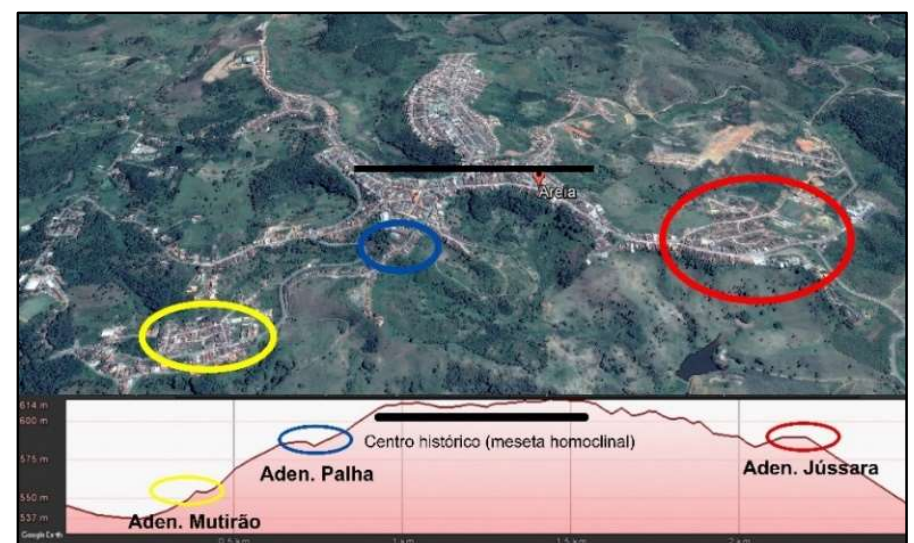

Figura 7: Adensamentos urbanos vulneráveis a risco em Areia/PB.

Foram identificadas três áreas, em concordância com o explicitado na figura 7, na periferia com interface geoambiental problemática à ocupação (vulnerabilidade), mas que apresentam adensamento urbano (áreas de risco). A primeira área recebeu o nome de Adensamento Jússara, conforme é mostrado na figura 8, e se localiza na zona Leste do Município, no bairro Jussara, na saída para Pilões (PB-087), João Pessoa (PB-079) e etc. Abrange as Ruas: Aurélio de Figueiredo, Dr. Castor Gondin, Antônio Apolinário, Praça do Trabalho, Antônio de Azevedo Maia, Floriano Peixoto e Conjunto Rua da Lama. Nesta área a altitude tem uma variação 590-540 m, a declividade forma terrenos ondulados e forte ondulados, apresentando três morros mesetados com encostas abruptas até os pedimentos em torno de um vale.

$\mathrm{O}$ adensamento urbano começa no topo do morro e acompanha a topografia de forma problemática até a várzea. Averígua-se que não houve no processo de loteamento o incremento medidas de contenção a movimentos de massa, como curvas de nível e as residências aparentemente são frágeis face ao contexto geoambiental de um terreno íngreme, com perfis de solo exposto de até $60 \mathrm{~m}$ e cobertura vegetal formada principalmente por bananeira (Musa spp) e Jaqueira (Artocarpus heterophyllus). 
Além disso não há um programa de saneamento básico eficaz, onde há vazamentos corrente de água e esgotos correm a céu aberto penetrando no solo. Dessa forma, uma paisagem urbana de risco, vulnerável a movimentos gravitacionais de massa e risco hidrológico, como rastejos, escorregamentos e corridas, além do efeito domino sob as construções.

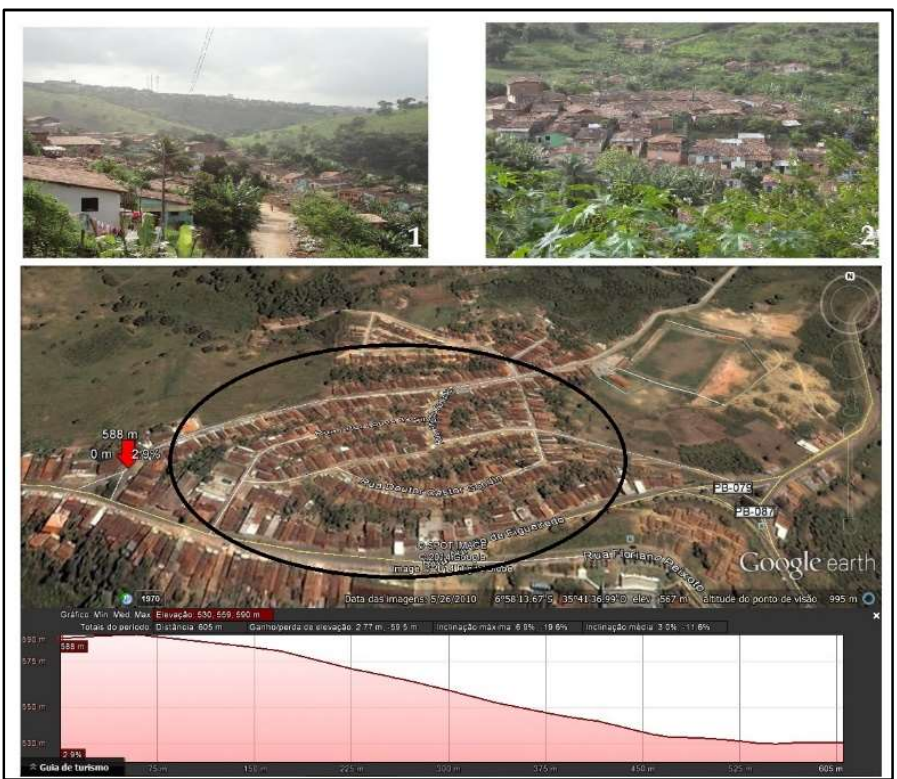

Figura 8: Adensamento Jússara do sitio urbano de Areia/PB.

A segunda área recebeu o nome de Adensamento Palha, consoante à figura 9. Localiza-se na zona Centro-Oeste do Município, no bairro Centro, na saída para Remígio, Campina Grande e etc (PB-079). Abrange as ruas: Abel da Silva, Praça Francisco Pereira Mariz, Belizio Gomes e João Lourenço. Nesta área a altitude tem uma variação $612-550 \mathrm{~m}$, a declividade forma terrenos ondulados e forte ondulados, apresentando uma encosta abrupta em torno de um vale principal. $O$ adensamento urbano se instalou desde o corte do morro para instalação da rua principal até as áreas mais íngremes, acompanhando a topografia de forma problemática, como no Adensamento Jussara. Dessa forma, uma paisagem urbana de risco, vulnerável a movimentos gravitacionais de massa e risco hidrológico, como rastejos, escorregamentos e corridas.

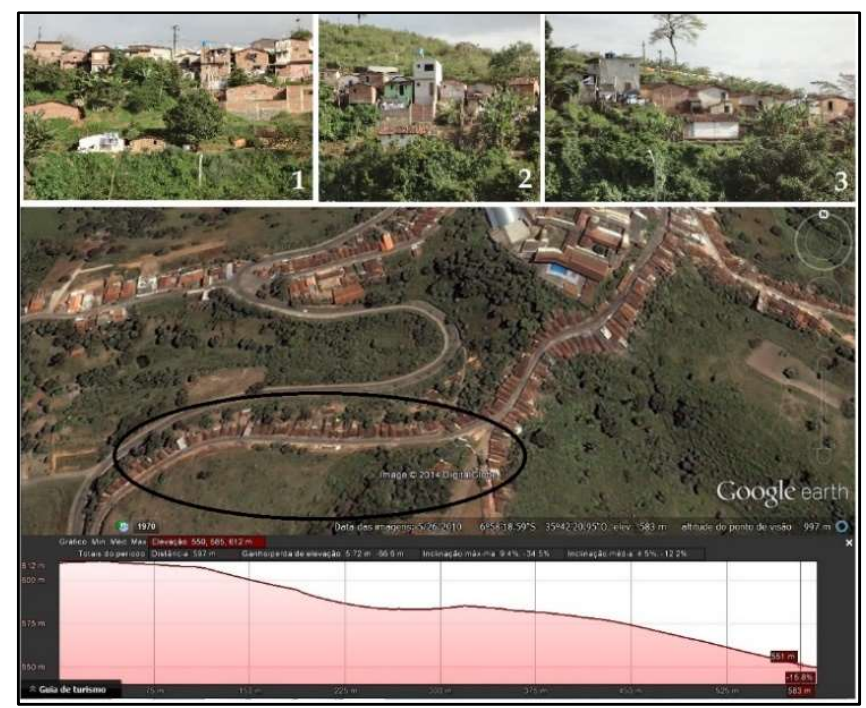

Figura 9: Adensamento Palha do sitio urbano de Areia/PB. 
A terceira área recebeu o nome de Adensamento Mutirão. Exposto na figura 10, localiza-se na zona Oeste do Município, no bairro Cidade Universitária, na saída para Remígio, Campina Grande e etc (PB-079. Abrange as ruas: José Rufino de Almeida, Carminha de Souza e Dom Adauto. Nesta área a altitude tem uma variação 651-531 m, a declividade forma terrenos ondulados e forte ondulados, apresentando uma encosta abrupta de um morro de topo íngreme. $O$ adensamento urbano se instalou desde o corte do morro para instalação da PB-79 até as áreas mais íngremes, acompanhando a topografia de forma problemática, como no Adensamento Jussara e Adensamento Palha. Dessa forma, uma paisagem urbana de risco, vulnerável a movimentos gravitacionais de massa e risco hidrológico, como rastejos, escorregamentos e corridas.

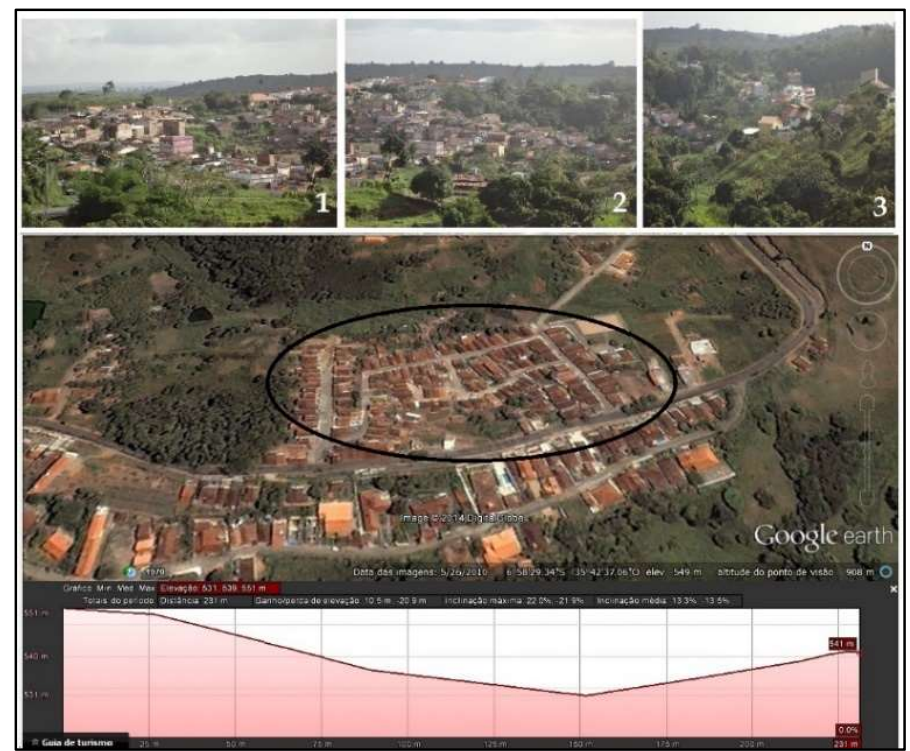

Figura 10: Adensamento Mutirão do sitio urbano de Areia/PB.

Ao verificar o perfil topográfico contido e a altitude da sede municipal $(620 \mathrm{~m})$ é perceptível que o adensamento urbano acompanhou a topografia montanhosa e acidentada da área de cima para baixo, ou seja, a sede está no platô (meseta) e a periferia segue o relevo íngreme até o fundo dos vales. Para Moraes et al. (2009), a ocupação das encostas, das áreas alagadiças e de preservação ambiental e cultural é um grave problema do município de Areia, "que compromete a segurança dos moradores e a paisagem da cidade, por descaracterizar o cinturão verde que rodeia toda a cidade e ocupar o relevo escarpado do terreno, provocando deslizamentos na estação chuvosa" (p.143).

Melo e Souza (2016) ao estudar as vulnerabilidades geomorfológicas em Garanhuns (PE), que também é um brejo de altitude, identificaram as mesmas problemáticas da área urbana de Areia, onde o relevo ondulado em forma de colinas, com cotas que chegam a ultrapassar $1.000 \mathrm{~m}$ de altitude, com a presença de vales, os quais estão tendo suas encostas utilizadas como área de expansão urbana e para prática de agricultura de subsistência. Que também foi identificado por Bastos e Peulvast (2016), no brejo de altitude de Baturite (CE).

Para Lima et al. (2016), no tocante aos processos superficiais que ocorrem brejo de altitude de Triunfo (PE), observou-se que os movimentos de massa tiveram papel essencial para a formação do colúvio na evolução da encosta na escala do Holoceno, porém, devido aos usos da terra, os processos erosivos têm contribuído para a gradativa perda do solo na encosta. Assim essas áreas necessitam que práticas 
conservacionistas sejam implementadas em contextos similares em todos os brejos de altitude do Nordeste do Brasil.

\section{CONCLUSÕES}

Ao comparar o arranjo do sítio urbano com as variáveis morfométricas: altitude, declividade, perfil topográfico e ao contrapor com o adensamento urbano observado na análise empírica, tem-se que as áreas mais vulneráveis são as da explosão demográfica (1901-2005), onde coparticipam construções urbanas seguras e construções urbanas problemáticas (estruturalmente frágeis face ao meio).

Mesmo com a vulnerabilidade desencadeada pelas características ambientais e de uso e ocupação no perímetro do sítio urbano, o Plano Diretor do município não traz soluções e mediações de urgência e longo prazo especificas há paisagem geomorfológica-urbana de risco. É plausível que essa pesquisa venha direcionar e possibilitar outras que aprofundem mais os levantamentos dos problemas de ordenamento territorial do sítio urbano de Areia, e possa subsidiar políticas públicas. Assim, o contexto Geoambiental observado em cada adensamento estudado repercute um dos principais problemas urbano nos brejos de altitude frente à expansão e ordenamento territorial em áreas ambientais vulneráveis e em risco eminente, que fica encoberto pelo poder publico vindo à tona apenas quando já ocorreu a catástrofe.

\section{REFERÊNCIAS}

AB'SABER, A.N.. A cidade de Manaus: Primeiros estudos. Boletim Paulista de Geografia, São Paulo, n.15, 1953.

AB'SABER. A. N.. O sítio urbano de Porto Alegre: estudo geográfico. Boletim Paulista de Geografia, São Paulo, n.42, 1965.

BASTOS, F. H.; PEULVAST, J. P.. Suscetibilidade à Ocorrência de Movimentos de Massa no Maciço de Baturité- Ceará, Brasil. Revista do Departamento de Geografia, Fortaleza, v.32, 2016.

CHRISTOPHERSON, R. W.. Geosystems: an introduction to physical geography. New York: MacMillan College Publishing Company, 1994.

EMBRAPA. Empresa Brasileira de Pesquisa Agropecuária. Sistema Brasileiro de Classificação de Solos. Brasília: EMBRAPA,1999.

FITZ, P. R.. Geoprocessamento sem complicação. São Paulo: Oficinas de Textos, 2008.

FLORENZANO, T. G.. Sensoriamento Remoto para Geomorfologia. In: Geomorfologia: conceitos e tecnologias atuais. São Paulo: Oficina de Textos, 2008.

KIMERLING, J.. Sistemas de Informações Geográficas e Cartografia. São Paulo: UNESP, 1994
LIMA, G. R.; MELO, L. V. O.; VITOR, A. R.. mapeamento geomorfológico de detalhe em uma parcela do quilombo Águas Claras - Triunfo/PE. Revista De Geociências do Nordeste, Natal, v.2, 2016.

MARQUES, A. L.; SILVA, D. G.; SILVA, J. B.. Refúgios úmidos do semiárido: um estudo sobre o brejo de altitude de Areia-PB. Revista Geotemas, Natal, v.4, n.2, 2014.

MELO, F. P.; ROSS, J. L. S.; SOUZA, R. M. E.. Modelagem de geoformas para mitigação do risco geoambiental em Garanhuns-PE. Acta Geográfica, Boa Vista, v.10, 2016.

MORAES, C. G. M. S. M.. Areia - Paraíba: morfologia e desenvolvimento urbano (séculos XVIII, XIX e XX). Dissertação (Mestrado em Desenvolvimento Urbano) Universidade Federal de Pernambuco, Recife, 2008.

MORAES, C. G. M. S. M.; MOREIRA, F. D.. O desenvolvimento urbano de Areia-PB: contribuição aos estudos de morfologia e história. Risco, São Carlos, v.9, 2009.

ROSS, J. L. S.. Análise Empírica da Fragilidade dos Ambientes Naturais e Antropizados. Revista do Departamento de Geografia, São Paulo, n.8, 1994. 
ROSS, J. L. S.. Geomorfologia Ambiente e

Planejamento. 2 ed. São Paulo: Contexto, 1991.

SAADI, A.. A geomorfologia como ciência de apoio ao planejamento urbano em Minas Gerais. In: SIMPÓSIO BRASILEIRO DE GEOGRAFIA FÍSICA APLICADA/1

FÓRUM LATINO-AMERICANO DE GEOGRAFIA FÍSICA

APLICADA, 7. Anais. Curitiba: UFPR, v.2. 1997.

SALOMÃO, F. X. T.. Controle e prevenção dos processos erosivos. In: Erosão e conservação dos solos: conceitos, temas e aplicações. Rio de Janeiro: Bertrand Brasil, 1999.

SANTOS, A. M. M.; TABARELLI, M.. Uma breve descrição sobre a história natural dos brejos nordestinos. In: Brejos de Altitude em Pernambuco e Paraíba: História Natural, Ecologia e Conservação. Brasília: 2004

SCHAEFER, C. E.. Análise Multi-Critério (MCE) aplicada ao mapeamento de áreas susceptíveis a movimentos de massa na área urbana de Viçosa-MG. SIMPÓSIO BRASILEIRO DE CIÊNCIAS GEODÉSICAS E TECNOLOGIAS DA GEOINFORMAÇÃO, 4. Anais. Recife, 2012.

SOCHAVA, V. B.. Por uma Teoria de classificação de geossistemas da vida terrestre. Biogeografia, São Paulo, n.14, 1978. 